\title{
Comments on Tue Trinh (2009) A constraint on copy deletion 1
}

JOSEF BAYER

The claim in Trinh's paper is that the lower copy of a movement chain can only be phonologically deleted if it ends a phonological phrase. The important issue here is that under present assumptions $\mathrm{X}^{\circ}$ can undergo topicalization to an $\mathrm{A}^{\prime}$-position as long as it occurs at the right edge of a prosodic phrase, essentially in disrespect of chain uniformity. The condition suggested appears in (1).

\section{(1) Prosodic Condition of Deletable Chains}

A chain $(\alpha, \beta)$ is deletable only if $\beta$ ends a phonological phrase

The empirical issue in the paper is mainly V-topicalization. Vtopicalization is said to occur in a language only if in underlying structure $\mathrm{V}$ occupies the right edge of a phonological phrase. The background assumption is that the VP matches rather directly onto a phonological phrase. Thus, in a head-final VP, V may be topicalized whereas in a head-initial VP, V cannot do so. If it does superficially, the true analysis must rely on remnant movement, i.e. movement of a VP from which other potential constituents have previously been removed. Trinh shows that in the languages under discussion (Dutch, German, Hebrew, Norwegian, Spanish, Swedish, Vietnamese and Yiddish) V-topicalization is island sensitive. An explanation of $\mathrm{V}$-topicalization as a consequence of remnant movement has become popular in syntax after the influential work of den Besten and Webelhuth (1987; 1990) and Müller (1998). However, it

\footnotetext{
1 I wish to thank Anne Kjeldahl and Jean Lowenstamm and Jürg Fleischer for their help with Danish and Yiddish data respectively and Martin Salzmann for comments. Any misconceptions are my fault, of course.
} 
was later shown that the connection between V-topicalization and scrambling is spurious. German allows this operation also in cases in which previous VP-evacuation can arguably not have taken place. ${ }^{2}$ Sharing this argumentation, Trinh suggests that UG indeed permits V-topicalization as one of its options, and that this operation rests on the requirement that movement may only take place from the right edge of a phonological phrase. V may also move if the condition in (1) is not met but then the lower chain link $\beta$ will be phonologically spelled out. Hebrew is identified as a language with a head-initial VP which allows V-topicalization but relies on pronunciation of the lower copy. The reason is that, Hebrew being $\mathrm{VO}, \mathrm{V}$ does not move from the right edge of VP (alias "prosodic phrase").

Let me first point out that I am sympathetic to the part of Trinh's approach by which rigid chain uniformity is given up in favor of a more dynamic account by which an $\mathrm{X}^{\circ}$ may under certain conditions also land in what X-bar theory has identified as a specifier position. Bayer and Brandner (2007) have argued that the reverse holds too. In SouthGerman dialects, a word size wh-element like was ("what") may undergo wh-movement to the C-position rather than to SpecCP and re-merge as a complementizer. A central piece of evidence is that such short whelements do not tolerate Doubly-Filled Comp (DFC), unlike unambiguous wh phrases such as wie lange ("how long") or mit wem ("with whom"). Another stream of evidence in this work is that clitics which move to the wh-filled C-position trigger phonological processes such as consonantal epenthesis which are unexpected and unexplained if the wh-element is in SpecCP to the left of a zero C-head as X-bar theory and strict chain uniformity suggest. ${ }^{3}$

Turning more closely to Trinh's article, my first question is what "ends" in (1) is supposed to mean. Dutch and German allow Vtopicalization but Trinh's argument can only succeed if the relevant phonological phrase from which $\mathrm{V}$ is extracted is identical with VP. In these languages (and presumably in any SOV-language in which auxiliaries follow V) the relevant phonological phrase would include more than VP proper. (2a) is an example from German for which (2b) provides an ele-

2 Cf. Fanselow (2002) among others.

3 For details which cannot be provided here for reasons of space see Bayer and Brandner (2007). 
mentary syntactic analysis and (2c) and (2d) potential prosodic analyses (for which we mark the right edge respectively with \#). Notice that (2e) is out under any reasonable phonological parse of (2a). ${ }^{4}$

(2) a. dass der Professor das Buch verschenkt hat that the professor the book donated has "that the professor has donated the book"

b. [CP dass [TP der Professor [vP das Buch verschenkt] hat]]

c. [dass der Professor \#] [das Buch verschenkt hat\#]

d. [dass der Professor \# [das Buch \#] [verschenkt hat \#]

e. *[dass der Professor \# [vp das Buch verschenkt \#] [hat\#]

Neither in (2c) nor in (2d) is there the right input that would allow (1) to apply. In each case, the phrase does not end with the verb $\beta$ that undergoes movement. Trinh warns in his note 4 that "prosodic structure $[\ldots]$ is quite remote from actual pronunciation". Whatever this may mean, I think one can hardly argue for some level of prosodic structure by which prosodic structure is exactly the same as syntactic structure. But even if $\beta$ in (1) can be interpreted such that the auxiliary is ignored, German still allows movement of a verb that obligatorily enters a V-cluster with a following lexical verb. ${ }^{5}$

(3) Abzuholen hat er sie immer an Wochenenden abzuholen gepflegt

to pick-up has he her always on weekends used

"As for picking-up, he always used to pick her up on weekends"

Given this, I suspect that (1) reduces to a statement about headedness in syntax, namely that the rightmost element of a syntactic phrase is deletable.

The issue is more than a matter of terminology. Consider Dutch or German VPs with a CP-complement. The complement is obligatorily to the right of V. (4b) is ungrammatical.

(4) a. Nur Hans hat angekündigt [dass er ins Kloster geht] only Hans has announced that he in-the monestary goes "Only Hans announced that he will join a monestary"

4 Cf. the Lexical Category Condition proposed in Truckenbrodt (1999) which exempts functional elements and their projections from phonological phrasing.

5 Pflegen only allows a left-adjacent $z u$-infinitive with which it forms a VV-complex. Neither scrambling nor extraposition of its complement is possible. 
b. *Nur Hans hat [dass er ins Kloster geht] angekündigt

c. [vp Angekündigt [CP dass er ins Kloster geht]] hat nur Hans [vP [angekündigt [ep dass er ins Kloster geht] hat

d. *[vp [cP dass er ins Kloster geht] angekündigt]] hat nur Hans [vp [ep dass er ins Kloster geht] angekündigt] hat

The contrast between (4c) and (4d) shows that his holds also for VPtopicalization. So we can be sure that the relevant order in VP is $\mathrm{V}<\mathrm{CP}$ rather than $\mathrm{CP}<\mathrm{V} .{ }^{6}$ If we retain the purely syntactic interpretation of (1) that Trinh's argumentation relies on, the prediction would be that [vp $\mathrm{V}$ $\mathrm{CP}]$ should either not allow V-topicalization at all or allow it only in the disguise of remnant movement, or resort to V-doubling. Fact is that Vtopicalization is as regular as in all the other cases.

(5) Angekündigt hat nur Hans [dass er ins Kloster geht] announced has only Hans that he in-the monestary goes

"Announced that he will join a monestary has only Hans"7

V-doubling as in Angekündigt hat nur Hans angekündigt dass er ins Kloster geht is out.

According to (1), (4) should be a case of remnant movement. But this entails that the CP has left VP via rightward movement. Apart from questions that emanated from the LCA (cf. Kayne, 1994), there is no evidence that $\mathrm{CP}$ has been merged with $\mathrm{V}$ such that a V-final VP results. There are different theories about $\mathrm{V}<\mathrm{CP}$ order in $\mathrm{OV}$-languages. According to

6 The pattern is universally very frequent. Many OV-languages have CP-complements which appear obligatorily in post-verbal position. One widely known example outside Germanic is Hindi. Even German has examples of predicates in whose presence CP is totally immobile, e.g. sich freuen ("to be glad").

(i) dass sich der Opa gefreut hat [dass die Enkel kommen] that REF the grandpa rejoiced has that the nephews come "that grandpa is happy that the nephews will come"

(ii) *[Dass die Enkel kommen] hat sich der Opa gefreut [ass Enkel kemmen] Even in these cases, $\mathrm{V}$ topicalizes as usually.

(iii) Gefreut hat sich der Opa [dass die Enkel kommen]

7 Due to the impossibility of V-topicalization, the English translation is not fully adequate. A paraphrase could be "As for announcing, only Hans announced that ..., while the others didn't say a word in public". 
LCA-based accounts (cf. Zwart, 1997: 65f.) $\mathrm{V}<\mathrm{CP}$ is the basic order. The verb is then topicalized from [Aux [vP V CP]] in violation of (1). If it is topicalized from the position to the left of Aux into which it would have to be raised according to the LCA-account, the OV/VO typology does not apply. In the latter case, prosody (in the phonological sense) would matter because [...V Aux] is certainly followed by a phonological phrase boundary \#. Since Trinh's arguments concern the linear organization of VP rather than the actual prosodic phrase, V-topicalization stranding a CP-argument seems to be a problem for the account.

A similar point can presumably be made with the help of data from NP-splitting. Trinh argues on the basis of Vietnamese data that $\mathrm{N}$ topicalization is optional, and that this optionality is explained by a dual analysis by virtue of which $\mathrm{N}$ can either combine with a restrictor PP directly or first combine with a classifier before combining with the restrictor PP. Only in the former case would there be a violation of (1). In the second case $\mathrm{N}$ plus classifier is thought to produce a phonological phrase. The phonological reasons for this are not discussed. I would expect them to be subtle. Let me introduce here an example from German in which $\mathrm{N}$ or NP arguably does not end a phonological phrase. As van Riemsdijk (1989) has shown, NP-splitting must be a case of movement because it responds to movement diagnostics. Consider the following case from German in which the DP ein Auto has left a residue in the middle field.

(6) Ein Autohat er sich keines aus JAPAN gekauft (sondern eines

a car has he REF none from Japan bought but one

aus DEUTSCHLAND)

from Gemany

"Concerning a car, he didn't buy one from Japan (but rather one from Germany)"

Ignoring the double occurrence of the determiner, the relevant structure is obviously as in (7).

(7) [Ein Auto] hat er sich [keines [ein Aute] aus JAPAN] gekauft

Due to the contrastive nature of (6), the prosodic structure of the DP from which movement takes place is in all likelihood (8a) and not (8b).

(8) a. [kein Auto aus JAPAN \#]

b. *[kein Auto \#] [aus JAPAN \#] 
So once again it seems that the right-edge condition of (1) can be circumvented, of course assuming that (1) has a status beyond the output of overt syntax. ${ }^{8}$

Questions also emerge with respect to weak pronouns and clitics which are known to move to the host that occupies the C-position, comp or the finite verb. Does the weak pronoun or clitic have a prosodic boundary \# when it is in situ? If it does, it can move without violating (1), and we expect what actually is the case. Consider example (9a) from Bavarian, a dialect which employs a system of pronominal clitics, and the rudimentary analysis in (9b).
a. G'seng hot -s bloss da Gustl seen has-it only the August
"As for seeing, only August has seen it"
b. [CP G'seng [ $\mathrm{C}^{\prime}$ hot-s [bloss da Gustl [vp -s g'seng] hot ]]]

According to (1), the clitic cannot escape VP unless it is an XP whose right edge is marked with the \# boundary. But if $-s$ is an NP why should it move? The reason for movement must be a clitic-independent one. Such a reason could be scrambling. But scrambling is conditioned by information structure and therefore in a sense "optional". In constrast to scrambling, clitic movement is mandatory, and there is no clear reason for associating it with information structure. ${ }^{9}$ Thus, the most parsimonious derivation starts from a structure as in (10) in which $\beta$, the clitic, does not end a phonological phrase.

$$
[\mathrm{DP} \text {...\#] [vp CL V \#] }
$$

Trinh observes that head adjunction in the form of V-to-T movement does not invoke doubling. He tries to explain this either via the assump-

$\overline{8}$ It is a tricky question whether $\mathrm{N}$ (Auto) moves after having combined with PP (aus $J A P A N$ ) - van Riemsdijk's notion of "regeneration" - or whether the actual antecedent in the splitting construction (the DP ein Auto) has already been present in underlyingly structure. I have a hard time making out phonological differences in phrasing. Notice that this question touches Trinh's argumentation but not mine because I take phonological structure to be less directly mapped onto syntax than the author.

9 Notice that (i), with the clitic unmoved, is completely inacceptable.

(i) *G'seng hot bloss da Gustl-s 
tion that head adjunction is universally left-adjunction or via the assumption that head movement leaves no trace at all. However, the Wackernagel-style cliticization seen in (9) is right-adjunction, and there is clear evidence that $\mathrm{V}$-to-C movement - a case of head-movement yields reconstruction effects. ${ }^{10}$

Let me finally turn to the V-doubling phenomenon that Trinh observes in Hebrew, Spanish, Vietnamese and Yiddish but not in Dutch, German and in the Skandinavian languages. The discussion involves two types of V-doubling, one in which the lower copy of the infinitival verb is pronounced in topicalization (the case of "double pronunciation", $+\mathrm{dp}$ ), as in (11), and and one in which the topicalized verb reappears as a finite verb in V2-position as in (12), (the case of "parallel chains", +pc). Both (11) and (12) are Trinh's examples from Yiddish.

(11) Gegessen hot Maks gegessen fish eaten has Max eaten fish

"As for having eaten, Max has eaten fish"

(12) Essen est Maks fish eat.INF eat.3SG Max fish

"As for eating, Max eats fish"

I share the conclusion that (11) and (12) reflect logically independent settings. I do not share the empirical generalization that German excludes the type in (12). As pointed out by Fleischer (2008), this type occurs also in Prussian Low German (Berlin, Baltic coastal reagion, Baltic German), in eastern and Siberian German minority languages as well as in Swiss Alemannic as spoken in the canton of Graubünden. In Standard German, the construction is usually missing because tun ("to do") steps in as a dummy verb that serves as a carrier of finiteness morphology in V2. As the contrast between (13a) and (13b) shows, tun is semantically interpreted in underlying position and thus incompatible with an individual-level stative

10 The most popular example is the licensing of the negative polarity verb brauchen ("to need"). If brauchen would not leave a trace in (i), it would be hard to explain how it can occur outside the scope of negation.

(i) Du brauchst die Suppe [NegP nicht [vP zu essen behst]]

you need the soup not to eat

"You don't need to eat the soup" 
predicate. It must be semantically empty in (13b) as it does not invoke semantic incompatibility with the stative predicate.
a. *dass er seinem Vater kaum ähneln
tut that he his father hardly resemble.INFL do.3SG
b. Ähneln tut er seinem Vater kaum resemble.INF does. $3 S G$ he his father hardly "As for resembling, he hardly resembles his father"

If the lexical verb has been topicalized, semantically empty dummy tun is normally inserted in order to satisfy the V2-constraint. In Yiddish and in the German dialects mentioned by Fleischer, the V2-requirement is resolved by insertion of the finite verb proper. There are examples which show that the finite verb does not need to be an exact copy of the topicalized verb. Fleischer quotes the following from $19^{\text {th }}$ century Prussian Lower German.

(14) Schifke schnuwe schnöfft hei nich man Branntwin supe snuff.N snuff.INF snuff.3G he not but brandy guzzle.INF söppt hei ser guzzle.3SG he very

"Snuff tobacco he does not but guzzle brandy he does a lot"

Here the topicalized material is an infinitival VP while the finite verb uses the verb of this VP as the carrier of finiteness. The same option exists in Hebrew, cf. Landau (2006) and work that he refers to. Given that there is no independent verb like German tun that could serve as the carrier of finiteness, doubling of the topicalized lexical $\mathrm{V}(\mathrm{P})$ is not surprising. ${ }^{11}$ Since German dialects - which I assume are by and large based on an OV-system like standard German - shows doubling of type (12), we can be sure that it is independent of the OV/VO word order parameter and rather related to V2 and the related fact that the finite verb appears in T-position in non V2-languages such as Spanish. ${ }^{12}$

For Yiddish and Scandinavian another factor may come into play which Trinh does not mention. According to Källgren and Prince (1989),

\footnotetext{
11 According to Landau (2006), Hebrew "lacks any do-support strategy".

12 Cf. example (98) in Trinh's article.
} 
the non-finite verbal form in Yiddish verb topicalizations is the stem of the finite verb plus the infinitival suffix -en, the so-called "pseudoinfinitive". ${ }^{13}$
a. veys -n veys-t er gornit know.INF know. $3 S G$ he nothing "As for knowing, he knows nothing"
b. bin-en bin ikh yetst a kabtsn am.INF am.1SG I now a pauper "As for being, I am now a pauper"
c. iz-n iz er yetst a kabtsn is. INF is. $3 S G$ he now a pauper
"As for being, he is now a pauper"

In the Scandinavian languages, VP-topicalization shows (or may show) a finite verb form. Källgren and Prince (1989) provide data from Swedish such as (16).

(16) Läs -er bok -en gör han nu read.3SG book.DEF does he now "Reading the book he is now"

The infinitival form would be läs-a. As Anne Kjeldahl (p.c.) points out to me, Danish also allows V-topicalization of an inflected verb.

(17) (John wanted to wash all the cars ...) men vask -et har han stet ingen but wash-PRET.3SG has he at-all none "but washed he has none at all"

The infinitival form would be vaske. So, in order to arrive at a more complete picture of $\mathrm{V}(\mathrm{P})$ topicalization one may want to know why the Scandinavian languages allow finite verbs or verbal projections to undergo topicalization, and why Yiddish makes use of the pseudo-infinitive, arguably a form related to the finite verb.

A separate challenge is type (11) where doubling occurs in the absence of finiteness. According to Fleischer, this construction is hardly ever

13 Data from Källgren and Prince (1989: 53); for references to earlier philological work see Fleischer (2008: 263). 
found in German dialects. So why should the lower copy not be deleted? According to Trinh, deletion would violate prosodic integrity as predicted by (1). Here one would like to explore how other varieties of Yiddish respond to the doubling option. As Santorini $(1992 ; 1993)$ has pointed out, older forms of Yiddish show far more OV-syntax, and there is evidence that $\mathrm{VO}$ and $\mathrm{OV}$ may even coexist in the grammar of a single speaker. (11) shows VO-order. The question is whether OV-order would systematically disallow doubling as in (18).

(18) Gegessen hot Maks fish gegessen eaten has Max fish eaten

"As for having eaten, Max has eaten fish"

If double pronunciation (infinitival doubling) is modeled according to Hebrew, the OV-based version shown in (18) could be an option. If double pronunciation is, however, the result of a deeper principle of the syntaxphonology interface as (1) suggests, a doubling version as in (18) should never arise. OV-based Yiddish would have to pattern along with German and not with Hebrew. Jean Lowenstamm (p.c.) informs me that (18) is in fact grammatical although it reflects a slightly older stage of the language. Thus, the prediction of (1) does not carry over to the OV-variety of Yiddish. In addition, double pronunciation can alternate with deletion. ${ }^{14}$ Is this a reflection of two grammars, one with V-topicalization and one with remnant VP-topicalization? I need to confine myself here to bringing up the question.

In conclusion, Trinh's attempt at constraining copy deletion continues a fruitful cross-linguistic debate that had been initiated by den Besten and Webelhuth (1987). The role of phrasal phonology is less obvious than suggested, and it needs to be seen how far the generalization about word order goes. Nevertheless, Trinh's article has brought up the right ques-

14 Jean Lowenstamm provides the following example. Suppose two individuals are being cross-examined by a police officer who asks them what they had drunk and what they had eaten in a particular restaurant at a particular time. One of the two answers:

(i) Ikh gedenk nisht mer af gevis vos mir hobn getrunken, nor gegesn hobn mir I remember not longer for sure what we have drunk but eaten have we fish ... af zikher...

fish for sure

"I don't remember with certainty what we drank, but we ate fish ... for sure ..." 
tions. I am sure it will stimulate both work in word order typology and theoretical work on interfaces.

\author{
University of Konstanz \\ josef.bayer@uni-konstanz.de
}

\title{
References
}

Bayer Josef and Ellen Brandner (2007), On Wh-Head-Movement and the Doubly filled Comp Filter. In Charles B. Chang and Hannah J. Haynie (eds.), Proceedings of the 26th West Coast Conference on Formal Linguistics. Cascadilla Proceedings Project, Somerville, MA, USA. 87-95.

den Besten, Hans and Gert Webelhuth (1987), Adjunction and Remnant Topicalization in the Germanic SOV-Languages. Paper presented at GLOW (Venice).

den Besten, Hans and Gert Webelhuth (1990), Stranding. In eds. Günther Grewendorf and Wolfgang Sternefeld (eds.), Scrambling and Barriers, Amsterdam: Benjamins. 77-92.

Fanselow, Gisbert (2002), Against remnant VP-Movement. In Artemis Alexiadou, Elena Anagnastopoulou, Sjef Barbiers and Hans-Martin Gärtner (eds.), Dimensions of Movement. From Features to Remnants. Amsterdam: Benjamins. 91-125.

Fleischer, Jürg (2008), Zur topikalisierenden Infinitivverdopplung in deutschen Dialekten: Trinken trinkt er nich, aber rauchen raucht er (mit einem Exkurs zum Jiddischen). Zeitschrift für Dialektologie und Linguistik 135. 243-268.

Källgren Gunnel and Ellen Prince (1989), Swedish VP-Topicalization and Yiddish VerbTopicalization. Nordic Journal of Linguistics 12. 47-58.

Landau, Idan (2006), Chain Resolution In Hebrew V(P)-fronting. Syntax 9, 1. 32-66.

Müller, Gereon (1998), Incomplete Category Fronting. Dordrecht: Kluwer.

van Riemsdijk, Henk (1989), Movement and Regeneration. In Paola Benincà (ed.), Dialectal Variation and the Theory of Grammar, Dordrecht: Foris.

Santorini, Beatrice (1992). Variation and Change in Yiddish Subordinate Clause Word Order. Natural Language and Linguistic Theory 10: 595-640.

Santorini, Beatrice (1993), Jiddisch als gemischte OV/VO-Sprache. In Werner Abraham and Josef Bayer (eds.), Dialektsyntax. Linguistische Berichte, Sonderheft 5. 230-245.

Truckenbrodt, Hubert (1999), On the relation between syntactic phrases and phonological phrases. Linguistic Inquiry 30. 219-255.

Zwart, Jan-Wouter (1997), Morphosyntax of Verb Movement: A Minimalist Approach to the Syntax of Dutch. Dordrecht: Kluwer. 